\title{
UNCOUPLED EVOLUTION OF MALE AND FEMALE CONE SIZES IN AN ANCIENT CONIFER LINEAGE
}

\author{
Gabriela Gleiser, ${ }^{1, *}$ Karina L. Speziale, ${ }^{*}$ Sergio A. Lambertucci, ${ }^{*}$ Fernando Hiraldo,† José L. Tella,† and Marcelo A. Aizen* \\ *Laboratorio Ecotono, INIBIOMA (CONICET-Universidad Nacional del Comahue), Quintral 1250, Bariloche 8400, Argentina \\ and +Estación Biológica de Doñana (CSIC), Avenida Américo Vespucio s/n, 41092 Sevilla, Spain
}

Editor: Patrick S. Herendeen

\begin{abstract}
Premise of research. Sexual functions in gymnosperms are mostly performed by separate reproductive structures, which largely reduces sexual interference and sets the scene for morphological and functional sexual specialization. The evolutionary trajectories followed by traits related to the male and female functions are therefore expected to be uncoupled. Studies on the fossil record of the conifer family Araucariaceae revealed important morphological changes occurring in reproductive cones. Here, we explored the pattern of evolution of male and female cone sizes in Araucariaceae, with a special focus on Arancaria - the most variable and widespread genus in the family.
\end{abstract}

Methodology. We gathered data on male and female cone sizes from fossils and extant Araucariaceae species. Focusing on Araucaria, we analyzed whether cone sizes are phylogenetically structured. Furthermore, we compared the evolutionary trajectories of male and female cone sizes by evaluating the goodness of fit of different evolutionary models. Finally, we evaluated whether different selective regimes across the phylogeny could have shaped cone morphology.

Pivotal results. Size changes in Araucariaceae occurred in both male and female cones, with the largest cones appearing in extant Araucaria. In this genus, different evolutionary models best described cone size changes, with male cone evolution best described by a model not influenced by phylogeny and female cone evolution by a stabilizing selection model with two optima. This resulted in contrasting phylogenetic signals, with female cone size being more phylogenetically structured than male cone size.

Conclusions. Changes in cone size in Araucariaceae occurred in both male and female cones. The largest male and female cones appeared in Araucaria through uncoupled evolutionary pathways, both involving a natural selection component as a driver of evolutionary change. A contrasting pattern of phylogenetic signal in male and female cone size reflected the uncoupled evolutionary trajectories followed by these sexual structures.

Keywords: Araucariaceae, cone size, genome size, models of character evolution, phylogenetic signal, seed size.

Online enhancements: appendix tables and figures.

\section{Introduction}

An outstanding feature of seed plants is their enormous diversity in reproductive structures. Even though most angiosperms are hermaphrodites (Renner 2014), an exceptional variability in sexual strategies that reduces interference between both sexual functions has evolved in the flowering plants (Barrett 2002, 2010). Sexual reproduction in gymnosperms is comparably much simpler; sexual functions are performed by separate re-

\footnotetext{
1 Author for correspondence; email: gabriela.gleiser@comahueconicet.gob.ar.

Manuscript received July 2018; revised manuscript received August 2018; electronically published December 5, 2018.
}

productive structures in most species, which reduces sexual interference to a great extent (although sexual conflict due to geitonogamy in monoecious species or due to intralocus sexual conflict in dioecious species may still occur; e.g., Delph et al. 2011). The evolution of reproductive structures in gymnosperms is then expected to be mainly related to successful pollen export in male reproductive structures and to the reception of pollen, complete seed development, and effective seed dispersal in female reproductive structures (Leslie 2011b). Consequently, because of these disparate functions, the evolutionary trajectories followed by male and female reproductive structures in gymnosperms are expected to differ.

Different evolutionary histories have been described for male and female cones in conifers (Leslie 2011a), by far the largest gymnosperm lineage. In this group, female cones in- 
creased relative tissue investment during the Mesozoic (as evidenced by the appearance of longer and more tightly packaged seed scales), while the relative investment in male cones seems to have remained almost unchanged over their evolutionary history. This evolutionary pattern was interpreted as a result of increasing animal seed predation pressures during the Mesozoic and Early Cenozoic (Leslie 2011a), while the apparent evolutionary stasis of the male cones in terms of morphology was assumed to be reflected by the fact that their main function (i.e., pollen release) remained the same across time (Leslie 2011b). Interestingly, Leslie (2011a) noted that Araucariaceae, which was likely a major food source for many megaherbivores during the Mesozoic given the high-energy yield of their leaves and their global distribution during the Jurassic (Hummel et al. 2008), was the first conifer family developing large female cones. The appearance of an araucarian large male cone in the late Cretaceous, comparable in size to some of the large pollen cones of the extant Araucariaceae species and notably larger than fossil male cones from older geological periods, prompted other authors to propose an evolutionary transition from small to large male cones in Araucariaceae (Stults et al. 2012). Although no hypothesis was proposed to explain the appearance of these large male cones, this discovery suggests that specific patterns of cone size evolution may have occurred within different conifer lineages.

In this study, we explore the pattern of variation in male and female cone size in the conifer family Araucariaceae. By gathering information on fossil cone length and width, we compared the patterns of change across time (i.e., evolutionary trajectories) in male and female cone size in the family. Furthermore, we profited from the availability of a dated phylogeny for Araucaria to estimate the phylogenetic structure of male and female cone size and compared their evolutionary trajectories by evaluating the goodness of fit of different models of character evolution. We show that evolutionary changes in cone size within Araucariaceae occurred in both male and female cones and, at least in Arancaria, that particular natural selection events seem to have played a role in driving the evolution of male and female cone size.

\section{Methods}

\section{The Family Araucariaceae}

Araucariaceae is a conifer family comprising monoecious and dioecious evergreen trees that occurs primarily in the Southern Hemisphere. As in most other conifers, its sexual functions are performed by separate reproductive cones. Both male and female cones are, on average, among the largest in conifers. Pollen grains are nonsaccate (i.e., without inflated air bladders and consequently with reduced floating capacity; Leslie 2010) and pollination drops are absent (Gelbart and Von Aderkas 2002); pollen tubes germinate outside the ovules (Tomlinson 1994). Seed scales in female cones are almost completely fused with bracts, with a single inverted seed per scale (Farjon 2017). Seed morphology is very variable in the family.

The family Araucariaceae may have originated in the Triassic; during the Jurassic it was a diverse family present in both Laurasia and Gondwana, while it disappeared from most parts of the Northern Hemisphere during the latest Cretaceous (Ker- shaw and Wagstaff 2001; Kunzmann 2007). The family is nowadays probably less diverse than it used to be, occurring in both South America and the southwestern Pacific region (Farjon 2017). Living species are grouped into three genera: Araucaria, with 19 species; Agathis, with 17 species (Farjon 2017); and the quite recently discovered monotypic genus Wollemia, defined as the sister taxon of Agathis (Kranitz et al. 2014), with individuals growing only within protected areas in southeastern Australia (Jones et al. 1995 in Kershaw and Wagstaff 2001). Arancaria is more geographically spread than Agathis, occurring both in southern South America and the South Pacific, while the latter is absent from South America. Also, interspecific differences among living Agathis species are smaller compared with differences among living Araucaria species (Kunzmann 2007). In particular, there is large variation in reproductive cone sizes in Araucaria (Farjon 2017); for example, average male cone length ranges from $2 \mathrm{~cm}$ (in Araucaria schmidii) to $25 \mathrm{~cm}$ (in Arancaria muelleri), average male cone width ranges from $0.3 \mathrm{~cm}$ (in Araucaria cunninghamii) to $5 \mathrm{~cm}$ (in Araucaria araucana), and average female cone diameter ranges from $4.5 \mathrm{~cm}$ (in Araucaria scopulorum) to $30 \mathrm{~cm}$ (in Araucaria bidwillii).

\section{Data Sources and Analyses}

We gathered data on male and female cone sizes of fossil and extant species of Araucariaceae. Data on the length and width of male and female fossil cones were obtained mostly from the compilation of Leslie (2011a), which was completed with data from other sources (table A1; tables A1, A2 are available online). Data on the length and width of male and female cones of extant species of genus Araucaria were extracted from Farjon (2017); the midpoint of the reported variation in size was used. Cone volume was approximated by estimating the volume of a prolate ellipsoid,

$$
\text { volume }=\frac{4}{3} \pi a^{2} b
$$

with $a$ and $b$ being half the width and half the length of the cone, respectively. This approximation has been shown to be a good predictor of cone dry mass in both male and female cones in conifers (Leslie 2011a).

Phylogenetic relationships and times of divergence among the 19 extant Araucaria species were obtained from Kranitz et al. (2014). The extant species in this genus have been arranged into four monophyletic sections (Escapa and Catalano 2013; Kranitz et al. 2014): section Araucaria, which includes A. araucana and Araucaria angustifolia; section Bunya, including A. bidwillii; section Intermedia, including Araucaria hunsteinii; and section Eutacta, which includes A. cunninghamii, Araucaria heterophylla, and the 13 species from New Caledonia (Arancaria bernieri, Arancaria biramulata, Arancaria columnaris, Araucaria humboldtensis, Araucaria laubenfelsii, Arancaria luxurians, Araucaria montana, A. muelleri, Araucaria nemorosa, Araucaria rulei, A. schmidii, A. scopulorum, and Araucaria subulata). The presence of phylogenetic signal in male and female cone length, width, and volume was assessed by estimating four different indices to account for the differential sensibility of these indices to the size of phylogeny, the assumption of an underlying evolutionary model, or the accuracy of the branch lengths (Münkemüller et al. 2012). First, we estimated Blomberg's $K$ (Blomberg 
et al. 2003) and Pagel's $\lambda$ (Pagel 1999), two indices formulated under an explicit Brownian motion (BM) model of trait evolution (see below) that have the advantage of providing a quantitative measure of the amount of phylogenetic signal relative to that expected under BM. A value of 0 indicates a random pattern of trait distribution, while a value of 1 reflects the amount of signal expected under BM evolution. Both indices were estimated using the function phylosig from the R package phytools (Revell 2012). In addition, we estimated Abouheif's $C_{\text {mean }}$ and Moran's I, two autocorrelation indices that make no assumptions about underlying evolutionary models but do not allow quantification of the amount of phylogenetic signal. These last two indices were estimated running the function moran.abouheif from the $\mathrm{R}$ package adephylo (Jombart et al. 2010), using the oriAbouheif and patristic proximity matrices for $C_{\text {mean }}$ and Moran's $I$, respectively. Significance of phylogenetic signal was assessed through randomization tests in all cases (i.e., with the null hypotheses being a lack of signal in all cases).

The evolutionary trajectories of male and female cone sizes were compared by evaluating the fit of four macroevolutionary models to the phylogeny and the data: BM, Ornstein-Uhlenbeck $(\mathrm{OU})$ process with a single optimum, early-burst (EB), and white noise (WN). Under BM, evolutionary changes are independent from one another and occur at a constant rate ( $\sigma^{2}$ parameter) with no preferred direction; as a result, trait mean remains constant but variance increases with time. This model would represent neutral drift or directional selection on a quickly varying environment (Hansen and Martins 1996). The OU model is an extension of the BM model in which the phenotypic space of trait variation is bounded, as values are attracted to a phenotypic optimum (in this case, the ancestral trait value); the strength of attraction, represented by the $\alpha$ parameter, increases with the distance of the trait value from the phenotypic optima (Hansen 1997; Butler and King 2004). This model would represent stabilizing selection constraining trait variation. In an EB model, the evolutionary rate, represented by the $a$ parameter, decreases or increases exponentially through time, such that trait variance is high toward the root of the phylogeny and low toward the tips, or vice versa. An EB model with decreasing evolutionary rates would mimic an adaptive radiation in which evolutionary change becomes increasingly constrained (Harmon et al. 2010). Finally, in a WN model the phylogenetic signal is erased and trait values are drawn from a single normal distribution. This model is an extension of the OU model in which the selection strength parameter $\alpha$ tends to infinity (Münkemüller et al. 2015). Models were run using the function fitContinuous from the $\mathrm{R}$ package geiger (Harmon et al. 2008), and their goodness of fit was compared by means of the small sample size corrected Akaike information criterion (AICc). We aimed to identify the single model that would best describe the evolution of a given trait across the phylogeny.

Given that the best-fitting evolutionary models describing female cone size evolution were the BM and OU models (see "Results"), we evaluated the possibility that different selective regimes could have shaped female cone morphology. For this, we compared the fit of a BM, OU with a single optimum (as the one described above) and an OU model with more than one optimum using the $\mathrm{R}$ package surface (Ingram and Mahler 2013). Importantly, this method has the advantage that it does not require an a priori adaptive hypothesis; instead, the position of the selective regimes is guided by the data. As the method performs better with multitrait data, we ran the analyses using the data on female length, width, and volume. Model selection was performed by comparing overall AICc values as above (see Ingram and Mahler 2013). To detect possible cases of convergent phenotypic evolution, we conducted both the forward and the backward phases of the analysis using the functions surfaceForward and surfaceBackward, respectively. All analyses and plots have been performed in R ( R Core Team 2018).

\section{Results}

Examination of the fossil record across geological periods revealed changes in male cone size over time in the family Araucariaceae (fig. 1). While the range of male cone size in extant Agathis overlapped the range of male cone size in extinct Araucariaceae, longer and wider male cones appeared in extant Araucaria. The same pattern was observed in female cones; size range of female cones in extant Agathis overlapped the size range observed in fossils, whereas larger female cones appeared in extant species of Araucaria. Male and female cone size in extant Wollemia nobilis were within the range observed in the fossil record in Araucariaceae.

Although changes in size occurred in both male and female cones, it seems these changes did not necessarily occur in parallel, as evidenced by relative cone size comparisons across sections within the genus Araucaria (fig. 2). Uncoupled size changes occurred in species belonging to all Araucaria sections, except in the two species from section Eutacta that do not occur in New Caledonia. Relative male cone size (in terms of both length and width) was greater than relative female cone size in Araucaria muelleri and Araucaria rulei, two species from New Caledonia. Similarly, relative male cone width was greater than relative female cone width in Araucaria araucana. The only species in which relative size was significantly greater in female cones than in male cones was Araucaria bidwillii, an Australian species with notably large female cones (up to $35 \mathrm{~cm}$ long and $25 \mathrm{~cm}$ wide; Farjon 2017).

Phylogenetic signal in cone length, width, and volume differed between male and female cones (fig. 3; table 1). While significant phylogenetic signal was found in all size measures in female cones, the distribution of male cone sizes across the phylogeny followed a random pattern; this pattern was consistent for the four estimates of phylogenetic signal (table 1). Selection of the best evolutionary models describing cone size evolution was consistent for the three size measures in both sexual functions. The best model representing the evolutionary trajectory followed by male cone size was the WN model, while both the BM and the single-optimum OU models had substantial empirical support (as defined by Burnham and Anderson 2002) in describing the evolutionary trajectory followed by female cone size (table 2). Moreover, the analyses conducted with the $\mathrm{R}$ package surface showed that an OU model with two optima outperformed both the single-optimum OU and the BM models (AICc for $\mathrm{BM}=79.66$; AICc for OU $=78.01$; AICc for OU with two optima $=36.65$ ) and identified one selective regime for the clade including sections Araucaria, Intermedia, and Bunya (the large-seeded clade; see "Discussion") and one selective regime for the clade including the rest of the species in the genus (table 3; fig. A1; figs. A1-A3 are available online). No instances of shared 

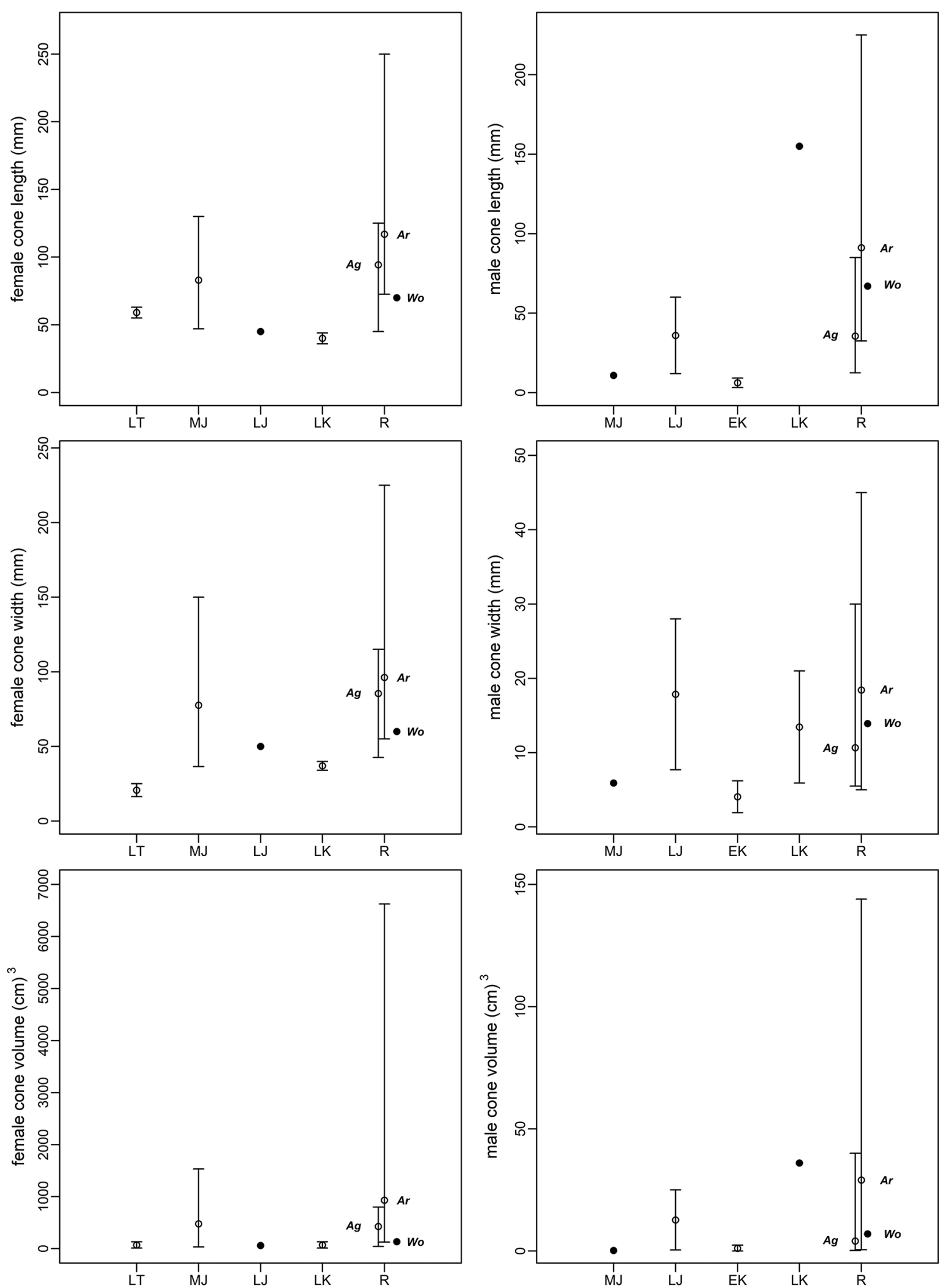

Fig. 1 Variation in female and male cone size across geological age, including both extinct and extant Araucariaceae species. Bars represent size ranges, open circles indicate mean values, and filled circles indicate cases in which only one fossil was found for a given geological age. Values from extant species were plotted separately for Araucaria, Agathis, and Wollemia and were slightly displaced for visual purposes. Ag $=A g a t h i s, A r=$ Arancaria, Wo $=$ Wollemia . Age abbreviations: $\mathrm{EK}=$ early Cretaceous, $\mathrm{LJ}=$ late Jurassic, $\mathrm{LK}=$ late Cretaceous, $\mathrm{LT}=$ late Triassic, $\mathrm{MJ}=$ middle Jurassic, $\mathrm{R}=$ recent. 

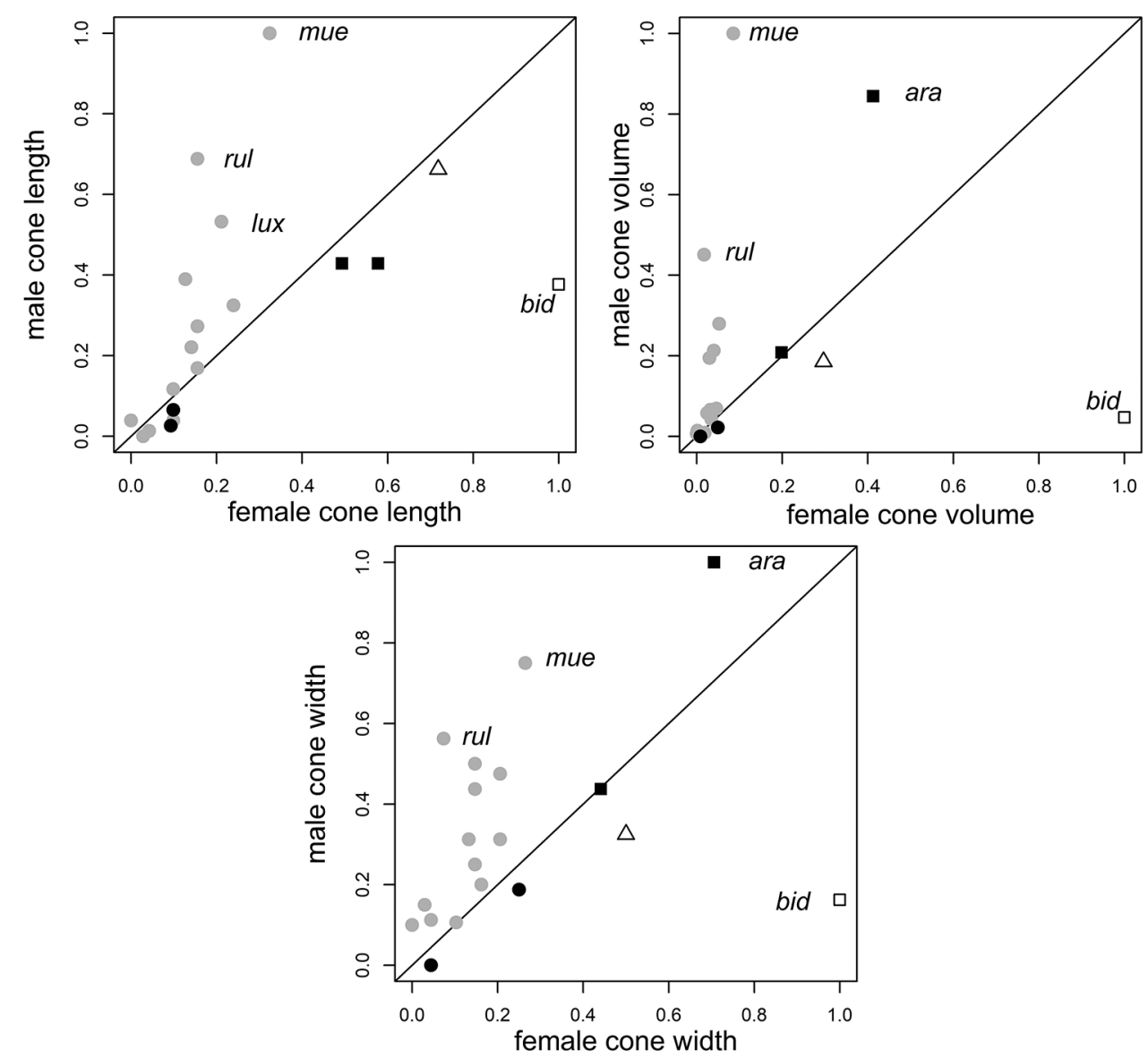

Fig. 2 Comparison between female and male relative cone sizes for Araucaria species. Cone sizes have been scaled to range linearly between 1 (highest) and 0 (lowest) by computing $z_{i}=\left[x_{i}-\min (x)\right] /[\max (x)-\min (x)]$. Departures from the dashed line (with slope $=1$ and $y$-intercept $=$ 0 ) indicate nonparallel changes in size. Species from section Araucaria are indicated with black squares, species from section Bunya with white squares, species from section Intermedia with white triangles, species from section Eutacta (excluding the New Caledonian species) with black circles, and species from section Eutacta from New Caledonia with gray circles. Ara $=$ Arancaria arancana, bid $=$ Arancaria bidwillii, lux $=$ Arancaria luxurians, mue $=$ Araucaria muelleri, $r u l=$ Araucaria rulei .

selective regimes resulting in convergent phenotypic evolution were found with this analysis.

\section{Discussion}

When plant sexual functions are performed by separate structures, the evolutionary trajectories of traits related to the male and the female functions can follow independent paths. Examination of data from the fossil record and from extant species of the conifer family Araucariaceae revealed changes in both male and female cone size, with the largest male and female cones in the family appearing in extant Araucaria. Although both male and female cone size increased, the evolutionary trajectories followed by the two types of cones differed - at least within the genus Araucaria.

The uncoupled evolutionary trajectories in size followed by male and female cones in Araucaria resulted in contrasting phylogenetic patterns, with female cone size being more phylogenetically structured than male cone size. Male cone size was randomly distributed along the phylogeny, and its evolution was best described by a WN model. Although the biological interpretation of this model is not clear (Münkemüller et al. 2015), the evolution of male cone size could have resulted from strong selective pressures acting even within lineages toward different optima, driving fast evolutionary changes that left no traces of shared evolutionary history among species. An association between male cone size and branch size was found in conifers globally (Leslie 2012), and it has been suggested that male cone size partly reflects the pattern of evolution of branch size. We think that it is more likely that selection would act primarily on reproductive cone size and that branch morphology would evolve in response to size changes in reproductive tissues for mechanical reasons (e.g., thick branches evolving to bear large cones). Eventually, studies on the role of possible abiotic or biotic drivers of such evolutionary changes (see below), and whether these drivers would act primarily on vegetative or reproductive structures, are clearly needed to understand the phylogenetically random pattern of variation in male cone size.

Female cones in Araucaria were noticeably larger in the clade including sections Araucaria, Intermedia, and Bunya, suggesting the evolution of an ancestor with large female cones for this clade. Leslie $(2011 a)$ proposed that the increase in female cone size in conifers reflected more investment in protective cone tissues (i.e., more robust cone scales), as average seed size remained similar 

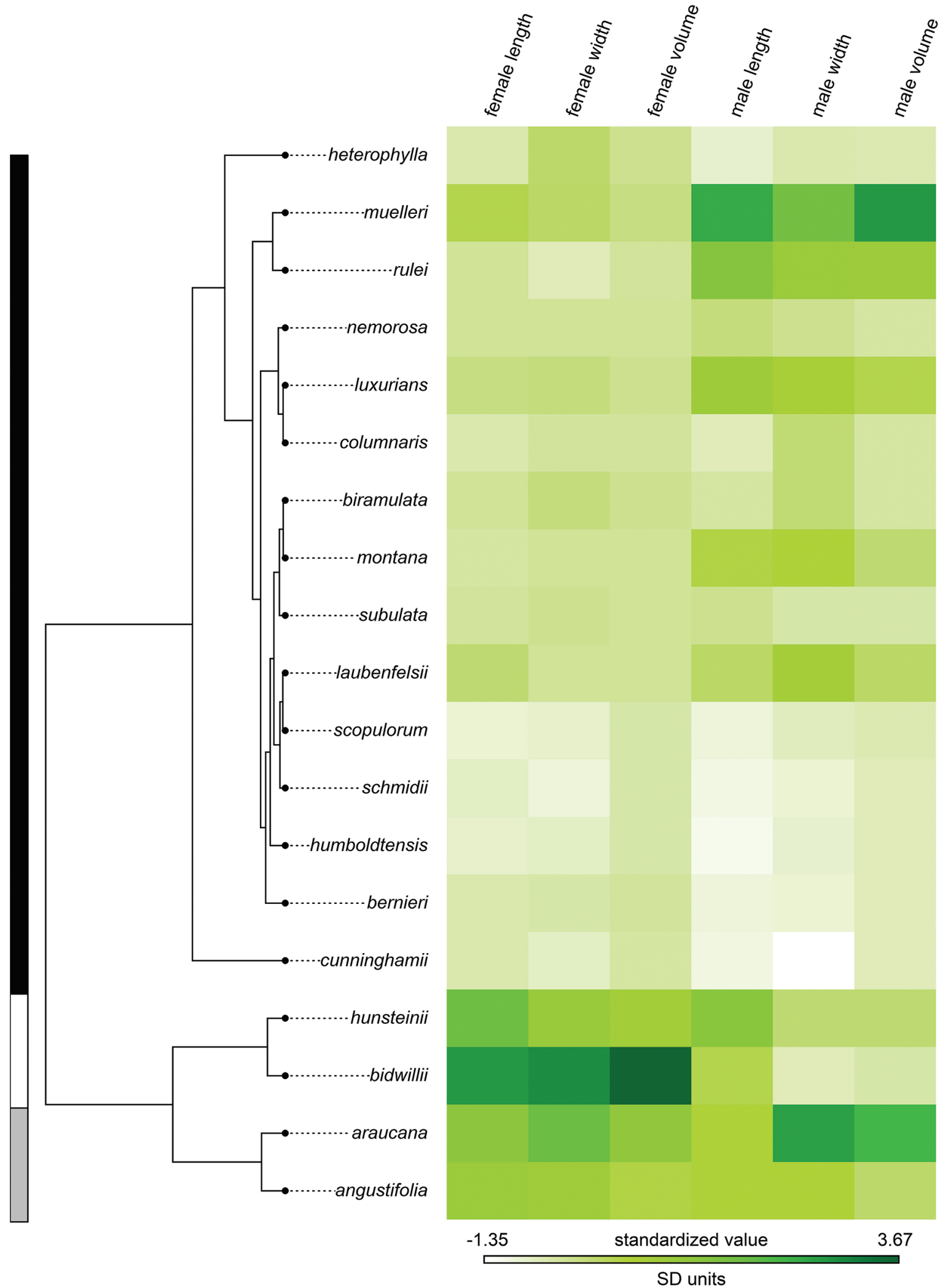

Fig. 3 Heat map showing standardized tip values for length, width, and volume of female and male reproductive cones of extant Araucaria species. Cells in the heat map represent species' standardized cone sizes and are colored with a gradient reflecting standard deviation units. Sections are indicated by the vertical bars on the left (in gray, section Araucaria; in white, sections Bunya and Intermedia; in black, section Eutacta). The heat map was drawn using the R package phytools (Revell 2012). 
Table 1

Phylogenetic Signal in Length, Width, and Volume of Male and Female Cones of the 19 Extant Araucaria Species

\begin{tabular}{|c|c|c|c|c|c|c|c|c|c|c|}
\hline \multirow[b]{2}{*}{ Cone type and measurement } & \multicolumn{2}{|c|}{ Blomberg's $K$} & \multicolumn{2}{|c|}{ Pagel's $\lambda$} & \multicolumn{3}{|c|}{ Abouheif's $C_{\text {mean }}$} & \multicolumn{3}{|c|}{ Moran's I } \\
\hline & K & $P$ & $\lambda$ & $P$ & $C_{\text {mean }}$ & SO & $P$ & Moran's $I$ & SO & $P$ \\
\hline \multicolumn{11}{|l|}{ Female cone: } \\
\hline Length & .518 & .002 & .896 & $<.001$ & .681 & 5.122 & .002 & .402 & 5.305 & .001 \\
\hline Width & .570 & .001 & .854 & $<.001$ & .593 & 4.503 & .001 & .327 & 4.584 & .002 \\
\hline Volume & .508 & .013 & .780 & $<.001$ & .460 & 4.239 & .001 & .236 & 4.631 & .002 \\
\hline \multicolumn{11}{|l|}{ Male cone: } \\
\hline Length & .092 & .196 & $<.001$ & 1.000 & .259 & 1.841 & .050 & .031 & .991 & .157 \\
\hline Width & .114 & .124 & .700 & 1.000 & .160 & 1.129 & .140 & $<-.001$ & .661 & .253 \\
\hline Volume & .155 & .114 & $<.001$ & 1.000 & .180 & 1.306 & .093 & .005 & .771 & .146 \\
\hline
\end{tabular}

Note. Both Blomberg's $K$ and Pagel's $\lambda$ are model-based indexes that take a value of 0 for a random trait pattern and a value of 1 for Brownian-motion evolution. For Abouheif's $C_{\text {mean }}$ and Moran's $I$, SO indicates deviation from random expectation. Statistical significance in all cases was evaluated with randomization tests in which the null distributions represented random trait variation.

across geological periods. In Araucariaceae, seed size increased through time, with some large-seeded species appearing in genus Araucaria (fig. A2). Interestingly, female cone volume in Araucaria increases with increasing seed volume (phylogenetic generalized least squares [PGLS] regression coefficient \pm SE: $0.685 \pm$ $0.075, P \ll 0.001$; for a description of this type of regression, see Paradis 2012). Again, large-seeded species appear mostly in the clade composed by sections Araucaria, Bunya, and Intermedia. Although the drivers of the evolution of large seeds in gymnosperms are still unknown, an association between large seeds and animal seed dispersal has recently been suggested (Leslie et al. 2017). Indeed, seed dispersal by different mammal and bird species was reported for the large-seeded species Araucaria araucana (Tella et al. 2016b), Araucaria angustifolia (Vieira and Iob 2009; Tella et al. 2016a; Dénes et al. 2018), and Araucaria bidwillii (Tella et al., forthcoming). Moreover, the recent findings that partial seed predation by seed-dispersing parrots enhances the germination of large-seeded Araucaria species (Tella et al. 2016a; Speziale et al. 2018) suggest that large seed sizes might have evolved to satiate parrots and other predators, thus facilitat-

Table 2

Goodness of Fit and Model Parameters of Alternative Evolutionary Models Describing the Evolution of the Male and Female Cone Length, Width, and Volumes in Araucaria

\begin{tabular}{lcccc}
\hline Cone type and measurement & Model & $\Delta_{i}$ & $w_{i}$ & Parameters \\
\hline Female cone: & BM & 2.606 & .185 & \\
Length & OU & 0 & .681 & $\sigma^{2}: .019 ; \alpha: .065 ; z_{0}: 12.83$ \\
& EB & 5.457 & .044 & \\
Width & WN & 4.051 & .090 & $\sigma^{2}: .011 ; z_{0}: 11.13$ \\
& BM & .575 & .386 & $\sigma^{2}: .015 ; \alpha: .041 ; z_{0}: 10.86$ \\
& OU & 0 & .515 & \\
Volume & EB & 3.425 & .093 & \\
& WN & 8.848 & .006 & $\sigma^{2}: .097 ; z_{0}: 873.93$ \\
& BM & 1.063 & .336 & $\sigma^{2}: .135 ; \alpha: .045 ; z_{0}: 801.11$ \\
Male cone: & OU & 0 & .571 & \\
Length & EB & 3.913 & .081 & \\
& WN & 7.761 & .012 & \\
& BM & 17.047 & 0 & \\
Width & OU & 2.850 & .194 & $\sigma^{2}: .333 ; z_{0}: 7.752$ \\
& EB & 19.897 & 0 & \\
& WN & 0 & .806 & \\
Volume & BM & 10.433 & .004 & $\sigma^{2}: .274 ; z_{0}: 1.613$ \\
& OU & 2.850 & .193 & \\
& EB & 13.283 & .001 & .802 \\
WN & 0 & .001 & .194 \\
\hline
\end{tabular}

Note. Model parameters are shown only for the models with strongest support. BM = Brownian motion, $\mathrm{EB}=$ early-burst, $\mathrm{OU}=$ Ornstein-Ulhlenbeck with a single optimum, $\mathrm{WN}=$ white noise. $\sigma^{2}=$ evolutionary rate, $\alpha=$ selection strength, $z_{0}=$ trait value at the root of the phylogeny. $\Delta_{i}$ is the difference in the corrected Akaike information criterion (AICc) values estimated between the AICc of a given model and the AICc of the best-ranked one $\left(\Delta_{i}=\operatorname{AICc}_{\mathrm{i}}-\mathrm{AICc} \min \right) . w_{i}=$ Akaike weights. 


\section{Table 3}

Parameters from the Ornstein-Uhlenbeck Model with Two Optima, as Estimated Using the R Package surface, Describing the Evolution of Female Cone Length, Width, and Volume in Araucaria

\begin{tabular}{lrrr}
\hline & Length & Width & Volume \\
\hline$\sigma^{2}$ & .655 & .049 & 8.027 \\
$\alpha$ & 14.303 & .700 & 16.486 \\
$\theta^{1}$ & 9.473 & 7.577 & 286.526 \\
$\theta^{2}$ & 19.343 & 16.361 & 2711.301 \\
\hline
\end{tabular}

Note. Analyses were run using log-transformed data; the values at the optima $(\theta)$ shown have been back-transformed. $\sigma^{2}=$ evolutionary rate, $\alpha=$ selection strength.

ing the germination of partially eaten dispersed seeds (Tella et al. 2016a). However, more research is needed for testing this hypothesis. In contrast, Leslie et al. (2017) found that the ancestral seed dispersal strategy of the clade composed by sections Araucana, Bunya, and Intermedia was animal dispersal and that there was a reversal to wind dispersal in Araucaria hunsteini. In this species, seeds are flattened and the seed scales are relatively large in comparison with seed scales from species in the other sections (Farjon 2017; van der Ham et al. 2010); however, to our knowledge, seed dispersal ecology has not yet been explored in this species. Estimation of phylogenetic signal in seed volume (table A2) shows a lack of phylogenetic structure in this trait; nonetheless, when A. hunsteini is removed from the analyses, phylogenetic signal significantly increases, lying well above the BM expected value of $K=1$. Furthermore, it is interesting to note that genome size (2C value), another key correlate of seed mass (for a general association in seed plants, see Beaulieu et al. 2007; for the association in pines, see Grotkopp et al. 2004), is phylogenetically structured in the genus Araucaria (table A2) and that the large-seeded clade also has the highest genome sizes (fig. A3). In addition, seed volume in Araucaria varies positively with genome size (PGLS coefficient \pm SE: $2.47 \pm 0.66 ; P=$ $0.002)$. We propose that the increase in genome size in the ancestor of the large-seeded clade could have allowed an increase in seed size, which was in turn also probably favored by the presence of animal dispersers preferring large seeds, and that these traits were inherited by the descendant species, with a reversal to wind dispersal in one of the species (Leslie et al. 2017). The observed changes in female cone sizes would then mostly reflect changes in seed size, with $A$. hunsteini retaining large female cones in spite of a derived reduction in seed volume.

According to our results, we can discard the fact that the evolution of male and female cone sizes would have occurred solely by neutral genetic drift, as both the WN model and the OU models include a natural selection component constraining phenotypic variation. It has been largely assumed that pollen dispersal in extant conifers is completely anemophilous, although recent research on $A$. araucana suggests that biotic pollination by parakeets may occur in this species, in which pollen cones are remarkably wider than in other Araucaria species (Gleiser et al. 2017). In this species, parakeets feed intensively on male cones and, having their bodies covered with pollen grains, perch on female cones without damaging the ovules contained in the cones. Wide male cones, probably associated with greater pollen production, could have evolved to offset pollen predation pressure. Although measures of trait variability and fitnessassociated measures are still lacking in A. araucana, these observations open the possibility that selection driven by pollinators could shape cone morphology in this species. Intriguingly, the pollen cones of the extinct conifer family Cheirolepidiaceae, although small, are also abnormally wide as compared with pollen cones of other conifers (Rothwell et al. 2007; Leslie 2011a), and insect pollination has been suggested to have occurred in this family (Labandeira et al. 2007). Finally, animal seed dispersal has recently been reported in species from the Araucaria large-seeded clade (see Vieira and Iob 2009; Tella et al. 2016a, 2016b, forthcoming; Dénes et al. 2018), suggesting that natural selection favoring large seeds could be shaping female cone morphology, at least in some species. Empirical studies like selection gradient analyses are required, however, to evaluate the hypothesis that natural selection could be influencing the evolution of male and female cone sizes in Araucaria.

In conclusion, there were changes in cone sizes over time in the conifer family Araucariaceae, where both male and female cone sizes increased-especially in Araucaria. In addition, changes in female cone size in this genus were probably related to changes in seed volume. Female cone sizes were more phylogenetically structured than male cone sizes. This pattern resulted from different evolutionary trajectories shaping cone sizes. In both pathways, natural selection played a role, at least in part, in modeling cone sizes.

\section{Acknowledgments}

We thank Edward Biffin for providing the Araucaria chronogram used in the analyses and Andrew B. Leslie for his feedback and comments on the manuscript. G. Gleiser, K. L. Speziale, S. A. Lambertucci, and M. A. Aizen are Consejo Nacional de Investigaciones Científicas y Técnicas career researchers.

\section{Literature Cited}

Barrett SCH 2002 Sexual interference of the floral kind. Heredity $88: 154-159$.

2010 Darwin's legacy: the forms, function and sexual diversity of flowers. Philos Trans R Soc B 365:351-368.

Beaulieu JM, AT Moles, IJ Leitch, MD Bennett, JB Dickie, CA Knight 2007 Correlated evolution of genome size and seed mass. New Phytol 173:422-437.

Blomberg SP, T Garland, AR Ives 2003 Testing for phylogenetic signal in comparative data: behavioral traits are more labile. Evolution 57:717-745.
Burnham KP, DR Anderson 2002 Model selection and multi-model inference: a practical information-theoretic approach. 2nd ed. Springer, New York.

Butler MA, AA King 2004 Phylogenetic comparative analysis: a modeling approach for adaptive evolution. Am Nat 164:683-695.

Delph LF, J Andicoechea, JC Steven, CR Herlihy, SV Scarpino, DL Bell 2011 Environment-dependent intralocus sexual conflict in a dioecious plant. New Phytol 192:542-552.

Dénes F, JL Tella, V Zulian, NM Prestes, J Martínez, F Hiraldo 2018 Combined impacts of multiple non-native mammals on two 
life stages of a critically endangered Neotropical tree. Biol Invasions 20:3055-3068.

Escapa IH, SA Catalano 2013 Phylogenetic analysis of Araucariaceae: integrating molecules, morphology, and fossils. Int J Plant Sci 174: 1153-1170.

Farjon A 2017 A handbook of the world's conifers. 2nd ed. Brill, Leiden.

Gelbart G, P von Aderkas 2002 Ovular secretions as part of pollination mechanisms in conifers. Ann For Sci 59:345-357.

Gleiser G, SA Lambertucci, KL Speziale, F Hiraldo, JL Tella, MA Aizen 2017 The southernmost parakeet might be enhancing pollination of a dioecious conifer. Ecology 98:2969-2971.

Grotkopp E, M Rejmánek, MJ Sanderson, TL Rost 2004 Evolution of genome size in pines (Pinus) and its life-history correlates: supertree analyses. Evolution 58:1705-1729.

Hansen TF 1997 Stabilizing selection and the comparative analysis of adaptation. Evolution 51:1341-1351.

Hansen TF, EP Martins 1996 Translating between microevolutionary process and macroevolutionary patterns: the correlation structure of interspecific data. Evolution 50:1404-1417.

Harmon LJ, JB Losos, TJ Davies, RG Gillespie, JL Gittleman, WB Jennings, KH Kozak, et al 2010 Early bursts of body size and shape evolution are rare in comparative data. Evolution 64:23852396.

Harmon LJ, JT Weir, CD Brock, RE Glor, W Challenger 2008 GEIGER: investigating evolutionary radiations. Bioinformatics 24:129-131.

Hummel J, CT Gee, K-H Südekum, PM Sander, G Nogge, M Clauss 2008 In vitro digestibility of fern and gymnosperm foliage: implications for sauropod feeding ecology and diet selection. Proc R Soc B 275:1015-1021.

Ingram T, L Mahler 2013 SURFACE: detecting convergent evolution from comparative data by fitting Ornstein-Uhlenbeck models with stepwise Akaike information criterion. Methods Ecol Evol 4:416425.

Jombart T, F Balloux, S Dray 2010 Adephylo: new tools for investigating the phylogenetic signal in biological traits. Bioinformatics 26:1907-1909.

Kershaw P, B Wagstaff 2001 The Southern conifer family Araucariaceae: history, status, and value for paleoenvironmental reconstruction. Annu Rev Ecol Syst 32:397-414.

Kranitz ML, E Biffin, A Clark, ML Hollingsworth, M Ruhsam, MF Gardner, P Thomas, et al 2014 Evolutionary diversification of new caledonian Araucaria. PLoS One, doi:10.1371/journal.pone .0110308

Kunzmann L 2007 Araucariaceae (Pinopsida): aspects in palaeobiogeography and palaeobiodiversity in the Mesozoic. Zool Anz 246: 257-277.

Labandeira CC, J Kvaček, MB Mostovski 2007 Pollination drops, pollen, and insect pollination of Mesozoic gymnosperms. Taxon 56:663-695.

Leslie AB 2010 Flotation preferentially selects saccate pollen during conifer pollination. New Phytol 188:273-279.

- 2011a Predation and protection in the macroevolutionary history of conifer cones. Proc R Soc B 278:3003-3008.

$2011 b$ Shifting functional roles and the evolution of conifer pollen-producing and seed-producing cones. Paleobiology 37:587602.

2012 Branching habit and the allocation of reproductive resources in conifers. Ann Bot 110:915-921.
Leslie AB, JM Beaulieu, S Mathews 2017 Variation in seed size is structured by dispersal syndrome and cone morphology in conifers and other nonflowering seed plants. New Phytol 216:429-437.

Münkemüller T, FC Boucher, W Thuiller, S Lavergne 2015 Phylogenetic niche conservatism: common pitfalls and ways forward. Funct Ecol 29:627-639.

Münkemüller T, S Lavergne, B Bzeznik, S Dray, T Jombart, K Schiffers, W Thuiller 2012 How to measure and test phylogenetic signal. Methods Ecol Evol 3:743-756.

Pagel M 1999 Inferring the historical patterns of biological evolution. Nature 401:877-884.

Paradis E 2012 Analysis of phylogenetics and evolution with R. 2nd ed. Springer, New York.

R Development Core Team 2018 R: a language and environment for statistical computing. R Foundation for Statistical Computing, Vienna. https://www.R-project.org/.

Renner SS 2014 The relative and absolute frequencies of angiosperm sexual systems: dioecy, monoecy, gynodioecy, and an updated online database. Am J Bot 101:1588-1596.

Revell LJ 2012 phytools: an R package for phylogenetic comparative biology (and other things). Methods Ecol Evol 3:217-223.

Rothwell GW, G Mapes, J Hilton, NT Hollingworth 2007 Pollen cone anatomy of Classostrobus crossii sp. nov. (Cheirolepidiaceae). Int J Coal Geol 69:55-67.

Speziale KL, SA Lambertucci, G Gleiser, JL Tella, F Hiraldo, MA Aizen 2018 An overlooked plant-parakeet mutualism counteracts human overharvesting on an endangered tree. R Soc Open Sci 5: 171456.

Stults DZ, BJ Axsmith, TK Knight, PS Bingham 2012 The conifer Araucaria bladenensis and associated large pollen and ovulate cones from the Upper Cretaceous Ingersoll shale (Eutaw Formation) of Alabama. Cretac Res 34:142-148.

Tella JL, G Blanco, FV Dénes, F Hiraldo Forthcoming Overlooked parrot seed dispersal in Australia and South America: insights on the evolution of dispersal syndromes and seed size in Araucaria trees. Front Ecol Evol (invited contribution).

Tella JL, FV Dénes, V Zulian, NP Prestes, J Martínez, G Blanco, F Hiraldo 2016a Endangered plant-parrot mutualisms: seed tolerance to predation makes parrots pervasive dispersers of the Parana pine. Sci Rep 6:31709.

Tella JL, SA Lambertucci, KL Speziale, F Hiraldo $2016 b$ Large-scale impacts of multiple co-occurring invaders on monkey puzzle forest regeneration, native seed predators and their ecological interactions. Glob Ecol Conserv 6:1-15.

Tomlinson PB 1994 Functional morphology of saccate pollen in conifers with special reference to Podocarpaceae. Int J Plant Sci 155:699-715.

van der Ham RWJM, JWM Jagt, S Renkens, JHA van Konijnenburgvan Cittert 2010 Seed-cone scales from the upper Maastrichtian document the last occurrence in Europe of the Southern Hemisphere conifer family Araucariaceae. Palaeogeogr Palaeoclimatol Palaeoecol 291:469-473.

Vieira EM, G Iob 2009 Dispersão e predação de sementes da araucária (Araucaria angustifolia). Pages 85-95 in CR Fonseca, AF Souza, AM Leal-Zanchet, T Dutra, A Backes, G Ganade, eds. Floresta de Araucária: Ecologia, Conservação e Desenvolvimento Sustentável. Holos, Ribeirão Preto.

Zonneveld BJM 2012 Genome sizes of all 19 Araucaria species are correlated with their geographical distribution. Plant Syst Evol 298:1249-1255. 